notable omission is a section of quantitative experiments on spontaneous nucleus formation.

C. W. BunN

\section{Physiology of Breathing}

Comparative Physiology of Respiration. By John D. Jones. Pp. vi+202. (Edward Arnold: London, 1972.) £4 cloth; f2 paper.

OF all branches of comparative physiology, respiration has a special appeal to biologists. This is partly because of the great diversity of evolutionary adaptations, their range in vertebrates being wider in structure and function than those in, for example, the nervous or the cardiovascular system. Secondly, man may find himself in a variety of extreme conditions and environments in which it is the limitations of breathing which are the most obtrusive-in exercise, high altitude, diving, pollution and asphyxiation, and even in hot climates and outer space. This is presumably because the small size of our reserves of respiratory gases and the rapid effects of alterations in gas exchange cause more serious deterioration than does restriction of other bodily activities. In these conditions we may envy our animal cousins with different adaptations, and try to emulate them by artificial means. The study of the comparative physiology of respiration has flourished in recent years. The research has direct relevance not only to man in unusual conditions, but also to respiratory illness where our adaptations cannot cope adequately with disease processes.

Dr Jones's book never fails to excite interest in the zoological adaptations of respiration. It is avowedly teleological, and whether this is a fault or not can be argued. Oddly enough, teleology can damp down speculation, for if every adaptation is appropriate there is no need to look for deficiencies and disadvantages. Joseph Barcroft's attitude to teleology was complementary and may be preferable: that of noting the nature and degree of functional impairment that an evolutionary specialization may carry with it. The book is also deliberately biased in favour of respiratory pigments and gas transport to the neglect of mechanisms of breathing and tissue respiration. Strictly speaking, the word respiration is more applicable to the latter two processes.

These approaches are legitimate author's privilege. What is presumably not intended is the lack of up-to-date information on some topics. Acclimatization to high altitude has been profitably studied since 1964, the latest reference; foetal and neonatal respiration, surely an important aspect of comparative physiology, is almost ignored, as are recent studies on the nervous control of breathing and the mechanics of the respiratory apparatus. Some sections are inaccurate or confused; for example, the definitions of vascular resistance, the description of oxygen "buffering" by haemoglobin, and the role of peripheral chemoreceptors. There are errors in the references.

Somie of these are small criticisms, and all may be corrected. The great merit of Dr Jones's book is that it arouses interest and provokes thought. Undergraduates, research workers and teachers will be stimulated and educated by it. J. G. WIDDICOMBE

\section{Semiconductors}

Semiconductors and Semimetals. Edited by $\mathbf{R} . \mathbf{K}$. Willardson and Albert C. Beer. Volume 9. Modulation Techniques. Pp. xiii +574. (Academic: New York and London, June 1972.) \$29.50.

IT is often said that research on conventional semiconductors such as $\mathrm{Ge}, \mathrm{Si}$ or $\mathrm{GaAs}$ is nowadays merely a matter of dotting the i's and crossing the t's. Be that as it may, techniques are still emerging from work on these materials which are important in that they have wide applicability to the study of solids in general. This book deals with an excellent example of such a technique, namely the use of modulation methods for observing weak structure in the optical spectra of solids. Although the high sensitivity of modulation methods has been known to physicists for a very long time, they have only recently applied them in this way. The motivation has been an improved knowledge and understanding of the energy band structure of solids beginning with semiconductors.

Study of the band edges either side of the fundamental energy gap of a semiconductor is eminently feasible by straightforward transmission measure. ments such as absorption, magnetoabsorption, cyclotron resonance or Faraday rotation. However, at energies appreciably removed from the energy gap, the transmission becomes too small and recourse must be made to refiexion experiments. Unfortunately reflexion spectra are relatively diffuse, but the use of thermal, stress, electric or wavelength modulation lifts weak but sharp spectral features associated with critical points from the diffuse background. Assigning structure to particular critical points and hence determining their energies is assisted by the presence of symmetry breaking parameters either inherent in the modulation method or separately applied statically.

This ninth volume in the series Semiconductors and Semimetals will presumably find most usage as a source of reference. It will be a welcome addition to the bookshelves of research workers in the field. Most of the chapters are written by authors who have established international reputations; they include B. O. Seraphin, R. L. Aggarwal and I. Balslev. The physical content is generally of a high standard but the editors have failed to eliminate a great deal of repetition amongst the authors. Almost 1,000 references are included and a serious attempt has been made to bring the volume up to date by the inclusion of addenda added at the proof stage. Even so, developments are only covered up to and including 1970 and, inevitably I suppose, the book is already two years behind "the state of the art". Minor criticisms include excessive verbosity in the first chapter and a glib treatment of experimental aspects in places.

In conclusion, a major criticism of the series Semiconductors and Semimetals is the narrow coverage of material within the volumes published so far. They are almost exclusively about III-V compounds. Treatment of such topics as narrow band (hopping) and amorphous semiconductors is long overdue and semimetals should be given more emphasis to justify the series title.

A. K. WaLton

\section{Muscle Regenerates}

The Regeneration of Minced Muscles. By Brice M. Carlson. Pp. vii +128. (S. Karger: Basel, London and New York, 1972.) Sw. francs $49 ; £ 5.40 ; \$ 13.75$.

THIS book is volume four in the Monographs in Developmental Biology series published by S. Karger under the editorship of A. Wolsky. It is a short (128page) lucid account of a field of work in which the author has already established himself as a leading authority.

As well as describing his own work Dr Carlson describes the earlier Russian work on which his own observations are based and also gracefully acknowledges the as yet unpublished work of some of his graduate students.

While the book is dominantly histological in character considerations of gross anatomy, biochemistry and functional characteristics of muscle regenerates are discussed. The author's style is clear and direct, and the standard of illustrations is high.

A final chapter, entitled "Epilogue", poses several interesting questions for future study, and discusses the potential use of minced muscle techniques in traumatic surgery.

Unfortunately this slim volume is priced at $£ 5.40$, but even so is likely to be the authoritative work on the subject for some years to come.

A. J. Buller 